\section{TREATMENT OF ULCERS FROM LYING STILL.}

\author{
To the Editor of The LancET.
}

SIR,-Observing in your last number of The Lancer a new ointment for the cure of " ulcers from lying still," recommended by a German surgeon, I send to you the following case with reference to the same subject:-

I was called to attend a female, ætat. 22, last November, whilst suffering from an attack of acute rheumatism, accompanied with violent pain along the course of the sciatic nerve; she had already been under medical treatment for several weeks, and had been confined to her bed the whole of that time; she was greatly emaciated, and had repeated attacks of syncope daily; the lower part of the back over the sacrum was ulcerated to the extent of seven or eight inches in circumference; the pulse small and rapid, and countenance anxious. I directed the patient to lie on the side or abdomen, but she stated that the pain was so excruciating on changing her position (viz., lying on her back), that she could not possibly alter it. I was, therefore, obliged to content myself with applying pads to the dorsal region, to take off as much pressure as possible from the ulcerated surface; simple dressings were applied to the sore, and tonic treatment adopted. The ulceration, however, progressed, the integuments over the sacrum sloughed away, along with the periosteum and ligamentous structure; exfoliation of the bone likewise commenced.

The case being now desperate, and the patient still unable to change her position, I adopted the following plan - - A large sheet was folded, to about the breadth of fourteen or fifteen inches, and one end was passed nnder the loins, and then drawn up to the top of the bed, where it was firmly fixed. The other end of the sheet was elevated so as to raise the patient several inches from the bed, to take off all pressure from the ulcer; it was likewise fixed to the top. In fact, the patient was suspended by a sling; the plan answered admirably, and the ulcer soon filled with healthy granulations, and in the course of a few weels the patient was convalescent, and the ulcer healed. I am, Sir, yours, most obediently,

T. WILSON, M.R.C.S.L.

Hornsea, Jan. 18, 1843.

\section{INTERMITTENT FEVER.}

ABSENCE OF SPLENIC LESTON.-INFLUENCE OF SULPHATE OF QUININE. - SPECIFIC INFLUENCE OF MEDICINES IN DISEASE.

THE following clinical remarks were made lately by M. Recamier at the Hôtel Dieu, Paris :-

In St. Madeleine's ward is a patient with a quotidian intermittent, in whom the febrile access regularly occurs, yet there is no appreciable lesion of the spleen. No doubt such lesions are common in intermittent fevers; and Torti, who first made known the fact, has reported cases of spontaneous rupture of the spleen during their progress. But to conclude, thence, that alterations of the spleen stand to intermittent phenomena in the relation of cause and effect, is unfounded and illogical. They have no necessary connection. We see daily intermittent neuralgia, phlegmasia, \&c., without any morbid alteration of the spleen. We see, also, engorgement of the spleen last long after intermittent phenomena have disappeared, and sometimes become the cause of after serious diseases, such as ascites, for instance. On the occurrence of such diseases from such causes, sulphate of quinine is decidedly indicated, which, in large doses, is in general completely effectual in conquering these engorgements. No fact is better established than that this effect is produced by the employment of the sulphate unmixed ; and a proof of its effect may be at any time observed in the gradual diminution of the spleen, day by day, under the influence of this salt.

I may take this opportunity of remarking how greatly the action of a medicine differs according as it is or is not indicated. When substances are administered in conformity with a positive natural indication for their use, the system tolerates them to a very great extent. When, on the contrary, they are administered without being indicated, or in the face of contra-indication, they yield no therapeutic action, but exert a physiological effect more or less misplaced, - a kind of poisonous influence, in proportion to their strength, or the magnitude of their doses. Thence have arisen the lamentable results which have been lately witnessed (M. Recamier alludes to untoward events which have followed the use of large doses of quinine in the French hospitals). A rheumatic patient is poisoned with doses of sulphate of quinine, which individuals attacked by intermittent fever, chronic engorgement of the spleen, take with impunity-not to say benefit. In the Iatter case the indication exists, which does not in the former._Guzette des Hôpitaux.

** It would seem, then, from the remarks of our learned contemporary, that the sulphate of quinine, which has been so much lauded for the cure of intermittent fever, rheumatism, \&c., is only adapted for exhibition when those diseases are attended with engorgement of the spleen.

* M. Piorry states that the sulphate of quinine, when rendered soluble by the addition of a little sulphuric acid, is efficacious in removing splenic engorgement in much less doses and less time than without that adjunct.—Gaz, des Hop., Dec, 27. 